\title{
Research on ReDesign AND MANUfACtURING OF an Automatic Roll Cutting Machine
}

\author{
Tan Thang NGUYEN ${ }^{1}$, Manh Tuan BUI ${ }^{1}$, Thanh-Phong DAO ${ }^{2,3, *}$ \\ ${ }^{1}$ Faculty of Mechanical Engineering, Ho Chi Minh City Industry and Trade College, Ho Chi Minh \\ City, Vietnam \\ ${ }^{2}$ Division of Computational Mechatronics, Institute for Computational Science, Ton Duc Thang \\ University, Ho Chi Minh City, Vietnam \\ ${ }^{3}$ Faculty of Electrical \& Electronics Engineering, Ton Duc Thang University, Ho Chi Minh City, \\ Vietnam
}

*Corresponding Author: Thanh-Phong DAO (Email: daothanhphong@tdtu.edu.vn)

(Received: 17-Dec-2020; accepted: 21-Jan-2021; published: 31-Mar-2021)

DOI: http://dx.doi.org/10.25073/jaec.202151.312

\begin{abstract}
Textile-and-garment industry is one of the largest economic sectors in Vietnam, with 4000 enterprises and turnover of 20 billions US$D /$ year. Therefore, designing and manufacturing are essential tasks for roll fabric cutting machines to serve the textile and garment industry. First of all, theoretical calculations are formulated for an automatic roll cutting machine. Then, simulations are conducted by a combination of MITcalc and Catia softwares. A prototype of fabric cutting machine is manufactured and experiments are implemented. The experimental results show that the machine stably works and overcomes the disadvantages of the popular cutting machines with the core-free roll on the market. The results also found that the size tolerance is achieved about $\pm 0.5 \mathrm{~mm}$, and this ensures a good working quality. The designed machine has a significant contribution on the textile and garment area in decreasing the cost of the cutting process.
\end{abstract}

\section{Keywords}

Textile, fabric cutting machine, simulation, fabrication.

\section{Introduction}

According to the Vietnam Textile and Apparel Association (VITAS), the textile is currently one of the largest economic sectors with 4000 enterprises. This sector can reach 20 billions USD per year, accounting for 15\% of GDP of Vietnam [1]. Currently, Vietnam is in the top 5 exporting countries of the largest textile import in the world. Textile and garment products of Vietnam are present in 180 countries and regions around the world, such as the United States, Europe, and Japan.

The garment and textile industry are the second-largest export turnover in Vietnam. In 2019, the textile export value contributed to 16 percent of total GDP. According to VITAS, in 2019, Vietnam's garment and textile industry earned US\$39 billion from exports, a year-onyear increase of over 8.3 percent. According to the Ministry of Industry and Trade of Vietnam, the export turnover of the textiles and apparel sector in the first 7 months of 2020 is estimated at 16.18 billion USD [1].

There are many different stages in the manufacturing process of industrial garment products, one of these is cutting fabric rolls to print labels, company logos, or cut fabric borders. Currently, 
the demand for roll cutting machines of textile and garment companies are huge, but most of the cutting machines are imported from abroad with a relatively high cost.

On the other hand, a numerous number of patents on fabric cutting machine have been invented, including number US Patent 695103 by Heny [2], US763804 of Seiberling [3], US879675 of Roos [4], US2186583 of Groh [5]. Most of all invented machines have the same disadvantages that they cannot cut non-core rolls. In the process of cutting fabric rolls, there are problems of material loss, uneven cutting, and wrong size cut.

More recently, new fabric manufacturing technologies have been increasingly developed such as laser cutting and water-jet thanks to an increased productivity, accuracy, and cutting quality [6]. Another machine was proposed to develop a textile and clothing manufacturing [7]. Before a real production, a computer-aided design was integrated with garment design [8]. Then, a fabric spreading and cutting were designed [9]. In order to add a color to garments, dyeing process was suggested [10].

For an automatic roll cloth cutting machine, the mentioned fabric machines are not still suitable. It needs an alternative technique. So, this paper suggests an automatic roll cloth cutting machine that can cut fabric rolls without core, specifically in the garment industry. It can effectively improve the sewing process and cost. Firstly, theoretical calculations are formulated for an automatic roll cutting machine. Next, simulations are performed by a combination of MITcalc and Catia softwares. A prototype of fabric cutting machine is manufactured and experiments are carried out.

\section{Theory of operation}

Nowadays, there have been many different operating principles of cutting fabric rolls. In this study, a cutting machine without core is proposed.

In accordance with the general requirements of the garment industry and the actual condi- tions of equipment, a technology of cutting fabric is suggested, as shown in Fig. 1. It includes four parts as follows: (1) fabric rollers, (2) disc cutter, (3) piston, and (4) the chassis. In this principle, a disc cutter with the roll of fabric outside the roll.

With this technology, users can cut both core and non-core rolls. They also can quickly attach the fabric roll to machine. The product can be immediately removed from the machine during the operation, and then it can cut the next product. Besides, it can eliminate the possibility of the product being skewered because the cloth roll is always perpendicular to the cutter. Lastly, this machine is convenient in inspection and maintenance.

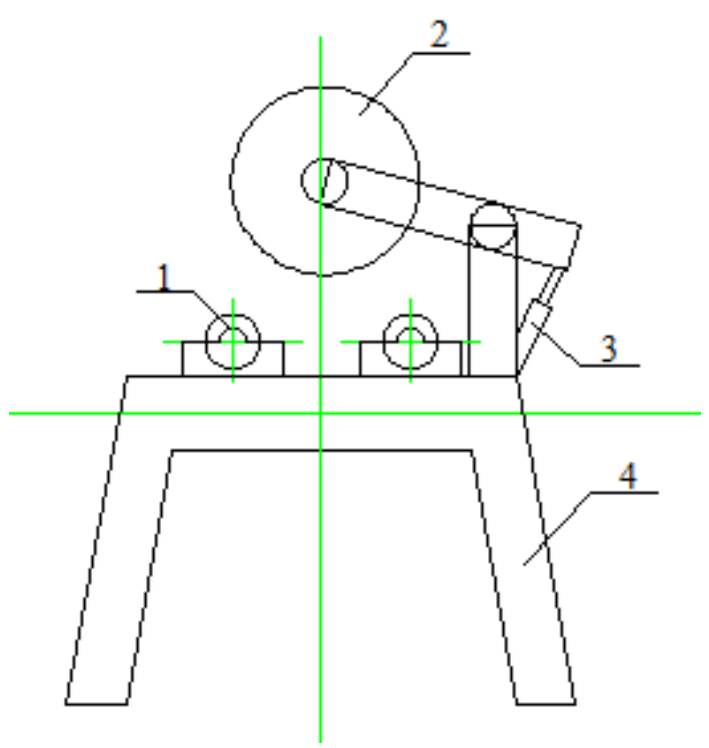

Fig. 1: Operating principle of Fabric cutting machine.

As given in Fig. 1, fabric rolls are placed on top of two fabric rollers (1) which are driven by a bottom motor via chain transmission. After the cutting position is determined, the disc cutter blade (2) is moved to the cutting position by means of a lead screw. The piston (3) moves the disc cutter blade in roll radial until the roll is completely cut. 


\section{Design and calculation construction}

\subsection{Calculation of lead screw}

With the use of moving the disc cutting blade table, lead screw can use roller friction or slip friction. Today, the ball bearing roller friction nut is widely used, especially in precision moving mechanisms, control systems, critical force transmission parts, high efficiency, and friction force. It depends on the speed but the transmission is expensive. It is usually not self-braking. The lead screw is often used to transmit large force with non-high precision, low cost, and selfbraking. With the not-so-high precision characteristics, the transmission type of sliding friction lead screw is chosen because clearance adjustment is relatively easy. Minor diameter, $d_{2}$, has been defined by Eq. (1) [11] as follows:

$$
\begin{aligned}
d_{2} & =\sqrt{\frac{F_{a}}{\pi \times[\rho] \psi_{H} \psi_{h}}}=\sqrt{\frac{F_{q t}+F_{m s}}{\pi \times[\rho] \psi_{H} \psi_{h}}} \\
& =\sqrt{\frac{570+600}{3.14 \times 8 \times 2.5 \times 0.5}}=5.2 \mathrm{~mm}
\end{aligned}
$$

in which: $d_{2}$ : minor diameter. $[p]$ : permissible pressure $(8 \mathrm{MPa})$.

In this study, $\psi_{H}=2.5 ; \psi_{h}=0.5$ are chosen. Supposing that the quantity of table is $60 \mathrm{~kg}=$ $600 \mathrm{~N}$, so coefficient of rolling friction $f=0,95$. Velocity of table is chosen as $0.5 \mathrm{~m} / \mathrm{s}$. So, the acceleration of the table is $10 \mathrm{~m} / \mathrm{s}$.

Since the screw length is chosen based on the gauge of $2000 \mathrm{~mm}$, the screw thread diameter (d) can be increased by approximately 4 to 5 times so that stability check is not required. In this study, some parameters are chosen as $d=$ $30 \mathrm{~mm}$, step of screw thread $t=6 \mathrm{~mm}$, and the $d_{2}=24 \mathrm{~mm}$. The working length of nut is determined as $l=2 d=60 \mathrm{~mm}$.

\subsection{Calculation and design of cutting structure}

\section{1) Calculation of the tool bearing shaft moment}

The force exerted on the fabric is calculated as follows:

$$
\begin{aligned}
P_{c} & =K \times f_{c} \times[\sigma]_{b} \\
& =1.75 \times 1 \times 21.25=37.245 \mathrm{~N}
\end{aligned}
$$

This cutting force must overcome the limit of the breaking strength of the fabric.

In which: $K$ is the reserve coefficient to increase the cutting ability of the tool. In this work, $K$ value is chosen as 1.75. $F_{c}$ is disc cutter section; $F_{c}=1 \mathrm{~mm}^{2}$, and $[\sigma]_{b}=21.25 \mathrm{~N} / \mathrm{mm}^{2}$ :

$$
\begin{aligned}
M_{x} & =\frac{P_{c} \times D_{t b}}{2}=\frac{37.245 \times 500}{2} \\
& =9311.25 \mathrm{~N} . \mathrm{mm}
\end{aligned}
$$

where $D_{t b}$ is maximum diameter of disc cutter $\left(D_{t b}=500 \mathrm{~mm}\right)$.

\section{2) Calculation of the power on the tool carrier}

The power on the tool carrier is computed as below:

$$
\begin{aligned}
& M_{x}=9.55 \times 10^{6} \times \frac{N}{n} \mathrm{~N} . \mathrm{mm} \\
& N=\frac{M_{x} \times n}{9.55 \times 10^{6}}=1.365 \mathrm{KW}
\end{aligned}
$$

in which

$$
n=\frac{60 \times 1000 \times V_{d}}{\pi \times D_{d}}=1400 \mathrm{rpm}
$$

with $V_{d}=37 \mathrm{~m} / \mathrm{s}, D_{d}=500 \mathrm{~mm}$ in which: $M_{x}$ is the tool bearing shaft moment; $N$ is the power of the tool carrier; $n$ is velocity of disc cutting by rpm; $V_{d}$ is velocity of disc cutting by $\mathrm{m} / \mathrm{s}$; and $D_{d}$ is diameter of disc cutting. 


\section{3) Calculation of cutting motor power}

The cutting motor power is calculated by:

$$
N_{c t}=\frac{N}{\eta}=1.5
$$

in which:

Machine powered by motor and V-belt, so $\eta=$ $\eta_{1}^{2} \cdot \eta_{2}^{2}$

Look up the Table 2-1 [11]:

Belt driver efficiency, $=0.96$

Ball bearing efficiency, $=0.995$

So, $\eta=0.96^{2} \times 0.995^{2}=0.91$

$N=1.365 \mathrm{KW}, \eta=0.91, N$ is the power of the tool carrier, and $\eta$ is mechanical efficiency. Based on the above data, the electric motor for the cutter is selected as $N=1.5 \mathrm{KW}$ and $n=$ 1450 rounds/min.

\section{4) Calculation of cutting tool carrier shaft}

Hole diameter of Cutting tool is chosen as $d=$ $25.4 \mathrm{~mm}$ and the bearing shaft diameter is about $30 \mathrm{~mm}$. MITCalc software is utilized to calculate the durability test for shaft with length $L$ of $260 \mathrm{~mm}$ and outside diameter $D_{n}$ of $32 \mathrm{~mm}$. The result of the minimum dynamic safety factor is 6.13 and deflection the largest is approximately $0.0111 \mathrm{~mm}$. So, the shaft ensures safety conditions. Figure 2 shows the results of calculation and testing of tool bearing shaft using MITcalc software.

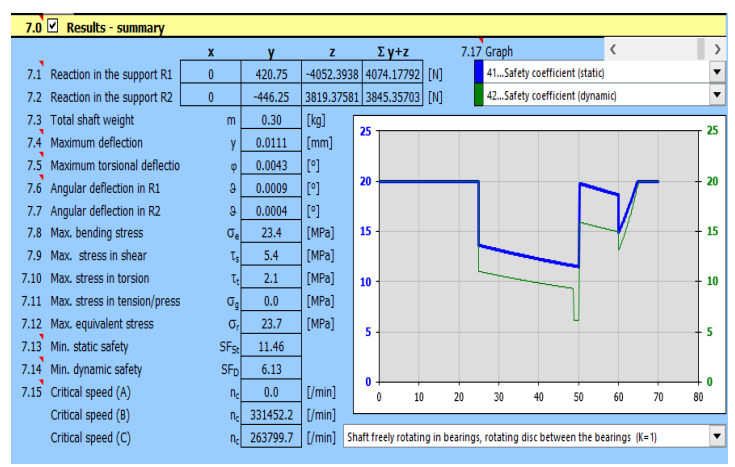

Fig. 2: Calculation and testing of tool bearing shaft using MITcalc software.

\section{5) Calculation and test of the durability of the chassis}

When the cloth cutting machine works, the cutting machine frame is affected by tightening forces. The force of cutting causes the machine frame to bend and cutting force causes the machine frame to bend horizontally. Meanwhile, the shearing force and weight of the components are placed on the machine cause the chassis to bend down. As shown in Fig. 2, a load of $70 \mathrm{~kg}$ is placed on the guide body of the cutter assembly. A maximum load of about $100 \mathrm{~kg}$ is applied to the two ends of the machine frame. When the machine was operated, the main force acting on the object from the cutting tool will be in the frame of the cutting tool and the shaft end. Therefore, for the computation of safety factor and displacement, the load should be put in three positions in Fig. 3. It illustrates load and simulation results of the chassis.

In Fig. 3b, the results show that the maximum von Mise stress is $19.64 \mathrm{MPa}$. The maximum displacement of the frame is $0.3899 \mathrm{~mm}$, as depicted in Fig. 3c. The minimum safety factor of the chassis is equal to 3, as shown in Fig. 3d. Thus, with the design of the chassis as a rectangular steel box of CT3, it meets the safety requirements.

\section{Test performance}

\subsection{Experimental arrangement}

After being assembled, the cutting machine is checked and run with no fabric roll. This is allowed to test the cutting with a number of different fabrics. It can test the durability of the structure, calibrate the machine, and select the machining parameters. Figure 4 fully describes the fabric cutting machine which is assembled on Catia software and actual machine.

Fabric cutting machine technological parameters include as follows: cutting tool speed $\left(V_{d c}\right)$, cloth roll speed $\left(V_{t q}\right)$, and cutting time $\left(t_{c}\right)$. According to technological parameters from the manufacturers of cutting machines, it can deter- 


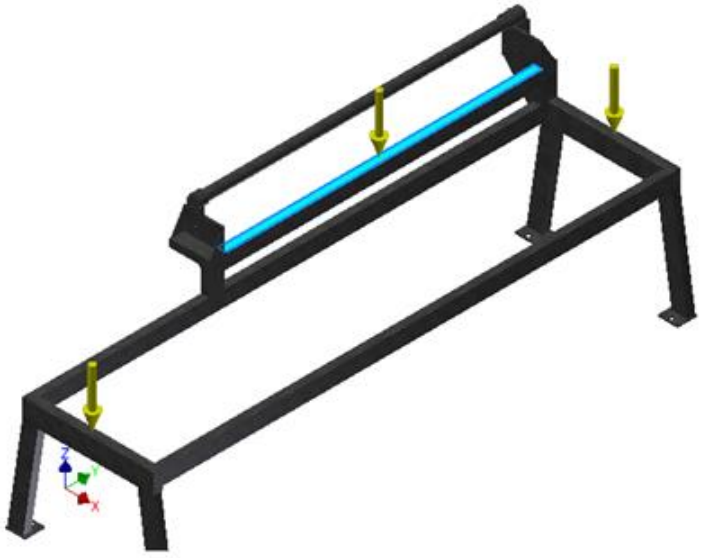

(a)

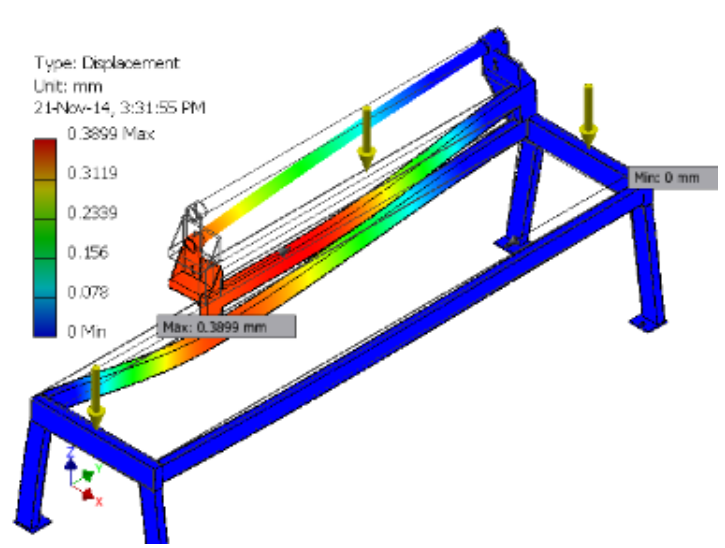

(c)

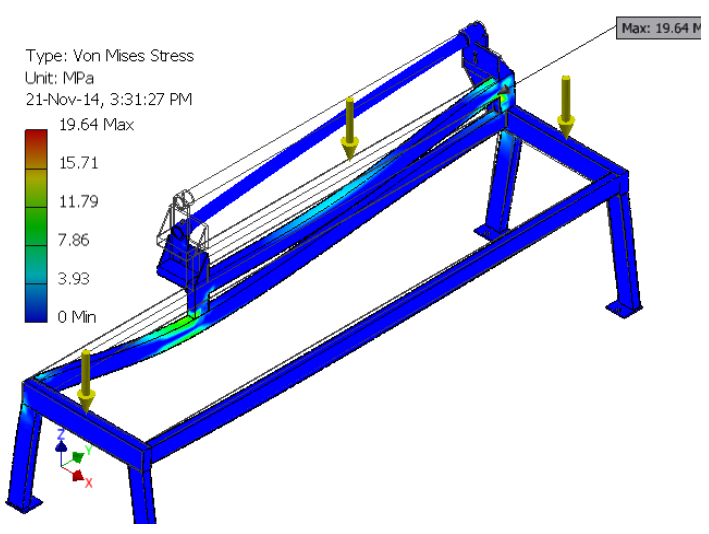

(b) Von Mises stress

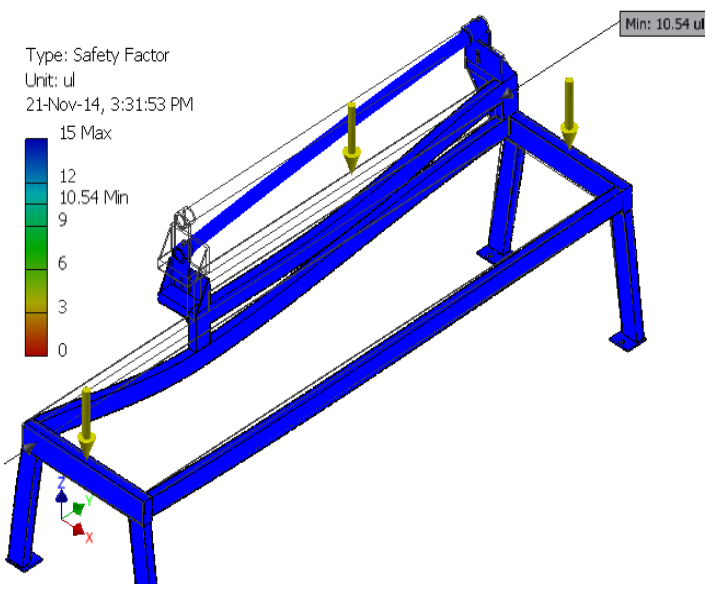

(d)

Fig. 3: Results of load analysis on the chassis: (a) load, (b) von Mise stress, (c) displacement, (d) safety factor.

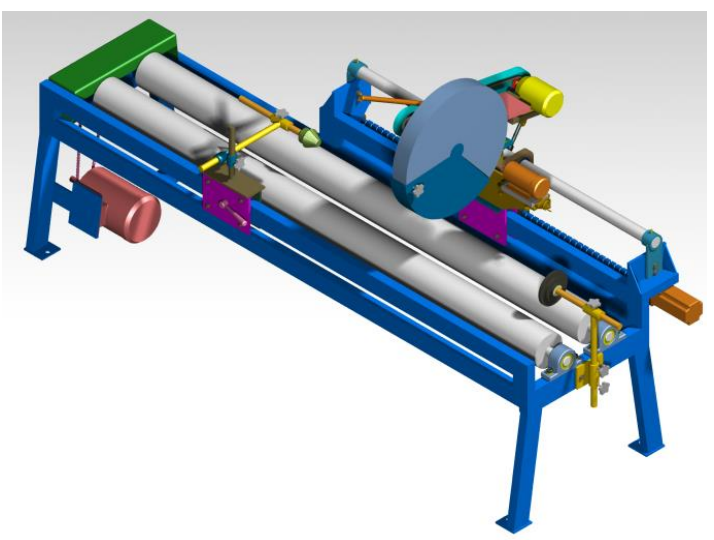

(a)

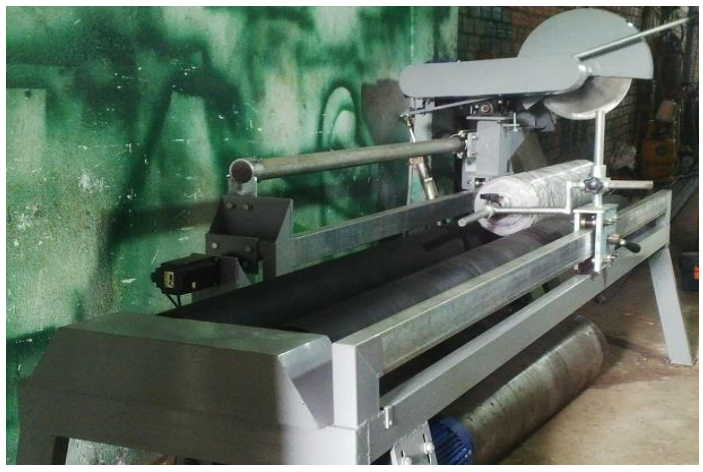

(b)

Fig. 4: Fabric cutting machine fully assembled: (a) Catia software, and (b) actual machine. 
mine the following parameters as:

$$
\begin{aligned}
& V_{d c M a x}=1600(\mathrm{rpm})=\frac{\pi \cdot D \cdot n}{60 \cdot 1000}=41.8(\mathrm{~m} / \mathrm{s}) \\
& V_{t q M a x}=60(\mathrm{rpm})=\frac{\pi \cdot D \cdot n}{60 \cdot 1000}=0.4(\mathrm{~m} / \mathrm{s})
\end{aligned}
$$

The results found that the fabric roll speed is about $0.9 \%$ compared to cutter speed. So, it doesn't affect too much the cutting process. Fabric rollers only have the meaning of rotating fabric roll so that the cutter can cut all rolls of fabric and just go of the roll diameter. According to the experiments, the fixed fabric winding speed, $V_{t q}$, is determined as $30 \mathrm{rpm}$.

Before preparing for automatic cutting, the experiment is carried out with two manual and automatic cutting modes. The manual cutting mode is used experiment to check the rigidity of the manual cutting device and the operation of other equipment. In addition, in the manual cutting mode, the longest time is 120 seconds. Cutting experiment was performed with $100 \%$ polyester fabric with diameter, $D$, of $150 \mathrm{~mm}$. Manual cutting results show that the range of cutting tool speeds from $100 \mathrm{rpm}$ to $800 \mathrm{rpm}$ has been achieved. However, with too long cutting time (more than 120 seconds), the cross-section and the cutting knife are subjected to a great friction. This results in a large heat generation, unsmooth cross-section, burning and sticking in some places.

\subsection{Results and discussion}

Test results of manual cutting and automatic cutting are given in Tabs. 1 and 2, respectively.

After the testing operation with two manual and automatic cutting modes, the results show that the machine structure works stably and the chassis is strong enough. Besides, the system is a precise control, the control interface is easy and reasonable. The cutting speed ratings are used for the tested fabrics as follows: $V_{d c}=100 \mathrm{rpm}$ - $800 \mathrm{rpm}, V_{t q}=30 \mathrm{rpm}$, cutting time $t=10 \mathrm{~s}-$ $40 \mathrm{~s}$, and diameters $D=150 \mathrm{~mm}-230 \mathrm{~mm}$.

Compare with the same machine in the market, it just has been half the price, as given in Tab. 3.
Tab. 1: Test results with manual cutting.

\begin{tabular}{|c|l|l|l|l|}
\hline No & Descriptions & $\begin{array}{l}V_{d c} \\
(\mathrm{rpm})\end{array}$ & $\begin{array}{c}t_{d c} \\
(\mathrm{~s})\end{array}$ & Result \\
\hline 1 & $\begin{array}{l}\text { Fabric 100\% } \\
\text { Polyester } \\
D=230 \mathrm{~mm}\end{array}$ & 300 & 30 & $\mathrm{O}$ \\
\cline { 2 - 5 } 2 & $\begin{array}{l}\text { Fabric 95.3\% } \\
\text { Cotton + 4.7\% } \\
\text { Spandex } \\
D=180 \mathrm{~mm}\end{array}$ & 500 & 20 & $\mathrm{O}$ \\
\cline { 2 - 5 } 3 & $\begin{array}{l}\text { Fabric 100\% } \\
\text { Polyester } \\
D=150 \mathrm{~mm}\end{array}$ & 100 & $\mathrm{O}$ & \\
\cline { 3 - 5 } & 600 & 120 & $\mathrm{X}$ \\
\hline
\end{tabular}

\begin{tabular}{|c|c|c|c|c|}
\hline No & Descriptions & $\begin{array}{l}\text { Vdc } \\
(\mathrm{rpm})\end{array}$ & $\begin{array}{l}\text { tdc } \\
\text { (s) }\end{array}$ & Result \\
\hline \multirow[t]{4}{*}{1} & \multirow{4}{*}{$\begin{array}{l}\text { Fabric } 100 \% \\
\text { Polyester } \\
D=230 \mathrm{~mm}\end{array}$} & 100 & 40 & $\mathrm{O}$ \\
\hline & & 300 & 30 & $\mathrm{O}$ \\
\hline & & 500 & 20 & $\mathrm{O}$ \\
\hline & & 700 & 10 & $\mathrm{O}$ \\
\hline \multirow[t]{4}{*}{2} & \multirow{4}{*}{$\begin{array}{l}\text { Fabric } 95.3 \% \\
\text { Cotton }+4.7 \% \\
\text { Spandex } \\
D=180 \mathrm{~mm}\end{array}$} & 200 & 40 & $\mathrm{O}$ \\
\hline & & 400 & 30 & $\mathrm{O}$ \\
\hline & & 600 & 20 & $\mathrm{O}$ \\
\hline & & 800 & 10 & $\mathrm{O}$ \\
\hline \multirow[t]{4}{*}{3} & \multirow{4}{*}{$\begin{array}{l}\text { Fabric } \\
\text { PE } 100 \% \\
\text { Polyester } \\
D=150 \mathrm{~mm}\end{array}$} & 100 & 40 & $\mathrm{O}$ \\
\hline & & 300 & 30 & $\mathrm{O}$ \\
\hline & & 500 & 20 & $\mathrm{O}$ \\
\hline & & 700 & 10 & $\mathrm{O}$ \\
\hline
\end{tabular}

Tab. 2: Test results with automatic cutting.

(Note: $O$ - Pass; $X$-Failure. The result is certified by the Textile Experiment Center of the Textile Institute in Ho Chi Minh City)

\section{Conclusions}

Based on the theoretical basis and the actual fabrication, testing the automatic roll fabric cutting machine has been manufactured to meet the initial design requirements. The results are drawn as follows:

- The results indicated that the machine structure works stably and the chassis is strong enough.

- The results indicated that the range of cutting tool speeds from $100 \mathrm{rpm}$ to $800 \mathrm{rpm}$ has been achieved. 
Tab. 3: Compare the quality charatetistics of the proposed machine with the same machine in the market.

\begin{tabular}{|l|l|l|l|}
\hline No & Details & $\begin{array}{l}\text { LQ-00 } \\
{[12]}\end{array}$ & $\begin{array}{l}\text { The pro- } \\
\text { posed } \\
\text { machine }\end{array}$ \\
\hline 1 & $\begin{array}{l}\text { Machine shaft } \\
\text { width }\end{array}$ & $1600 \mathrm{~mm}$ & $2650 \mathrm{~mm}$ \\
\hline 2 & Max cutting & $\varnothing 380 \mathrm{~mm}$ & $\varnothing 400 \mathrm{~mm}$ \\
\hline 3 & Cutting core & $\varnothing 1-3 \mathrm{inch}$ & $\mathrm{N} / \mathrm{A}$ \\
\hline 4 & $\begin{array}{l}\text { Cutting preci- } \\
\text { sion }\end{array}$ & $\pm 0.1 \mathrm{~mm}$ & $\pm 0.5 \mathrm{~mm}$ \\
\hline 5 & $\begin{array}{l}\text { Diameter of } \\
\text { circular blade }\end{array}$ & $\varnothing 450 \mathrm{~mm}$ & $\varnothing 500 \mathrm{~mm}$ \\
\hline 6 & Power & $5.5 \mathrm{KW}$ & $5.5 \mathrm{KW}$ \\
\hline 7 & Price & $\begin{array}{l}\text { US } \\
\$ 11,000- \\
13,500\end{array}$ & US $\$ 5,000$ \\
\hline
\end{tabular}

- The cutting speed ratings were found for the tested fabrics as follows: $V_{d c}=100 \mathrm{rpm}-800$ $\mathrm{rpm}, V_{t q}=30 \mathrm{rpm}$, cutting time $t=10 \mathrm{~s}-40 \mathrm{~s}$, and diameters $D=150 \mathrm{~mm}-230 \mathrm{~mm}$.

- The machine was designed with a guaranteed aesthetic appearance.

- The machine used a PLC programmable control system.

- The adjustment parts are arranged appropriately for easy and quick adjustment.

- The safety system in the machine is fully designed and ensuring the safety of workers when working with the machine.

- Lastly, this study also significantly contributes in reducing the cost of the machine.

\section{Acknowledgements}

This research is funded by Vietnam National Foundation for Science and Technology Development (NAFOSTED) under grant number 107.01-2019.14.

\section{References}

[1] Nguyen, T. (2020). Seizing Investment Opportunities in Vietnam's Garment and Textile Industry.

[2] Heany, J.A. (1902). U.S. Patent No. 695,103 . Washington, DC: U.S. Patent and Trademark Office.

[3] Seiberling, F.A., \& Smith, U.P. (1904). U.S. Patent No. 763,804. Washington, DC: U.S. Patent and Trademark Office.

[4] Roos, A. (1908). U.S. Patent No. 879,675. Washington, DC: U.S. Patent and Trademark Office.

[5] Groh, E.H. (1940). U.S. Patent No. 2,186,583. Washington, DC: U.S. Patent and Trademark Office.

[6] Vilumsone-Nemes, I. (2018). Automation in spreading and cutting. Automation in Garment Manufacturing. Woodhead Publishing, 139-164.

[7] Shih, W.Y.C., \& Agrafiotis, K. (2015). Competitive strategies of new product development in textile and clothing manufacturing. The Journal of the Textile Institute $106(10), 1027-1037$.

[8] Jhanji, Y. (2018). Computer-aided design-garment designing and patternmaking. Automation in Garment Manufacturing. Woodhead Publishing, 253-290.

[9] Vilumsone-Nemes, I. (2015). Fabric spreading and cutting. Garment Manufacturing Technology. Woodhead Publishing, 221-246.

[10] Sarkar, A.K. (2015). Dyeing technologies for denim garments. Denim. Woodhead Publishing, 271-285.

[11] Hiep, N.T. (2008). Machine parts Design: Vietnam Education.

[12] LIANQI. Low Price High Speed Paper/Film Roll Cutting/Slitting machine. Available: https://kslianqi.en.made-inchina.com/product/hyWmxoZcLIVN/ChinaLow-Price-High-Speed-Paper-Film-RollCutting-Slitting-Machine.html 


\section{About Authors}

Tan Thang NGUYEN is currently a lecture at the Mechanical Engineering Faculty, Ho Chi Minh city Industry and Trade College, Ho Chi Minh City, Vietnam. He received his B.S. degree in mechanical engineering from the Ho Chi Minh City University of Technology and Education, Vietnam in 2008. He received his M.S. degree in mechanical engineering from the National Kaohsiung University of Applied Sciences, Taiwan, ROC, in 2011. His research interests include compliant mechanism, rehabilitation, mechanical engineering for textile industry, and optimization algorithm.

Manh Tuan BUI is currently a lecture at the Mechanical Engineering Faculty, Ho Chi Minh city Industry and Trade College, Ho Chi Minh City, Vietnam. He received his B.S. degree in mechanical engineering and automobile engineering from the Ho Chi Minh City University of Technology and Education, Vietnam in 1995 and 1997, respectively. He received his M.S. degree in mechanical engineering from the Ho Chi Minh city University of Technology, Vietnam in 2001. His research interests include mechanical engineering for textile industry, harvesting technology agriculture, and optimization algorithm.

Thanh-Phong DAO is currently an assistant professor at the Institute for Computational Science, Ton Duc Thang University, Ho Chi Minh City, Vietnam. He received his B.S. degree in mechanical engineering from the Ho Chi Minh City University of Technology and Education, Vietnam in 2008. He received his M.S. and Ph.D. degree in mechanical engineering from the National Kaohsiung University of Applied Sciences, Taiwan, ROC, in 2011 and 2015, respectively. His research interests include compliant mechanism, assistive technology and rehabilitation, and optimization algorithm. 